\title{
The modelling prediction of Haul Road Surface Deflection
}

\author{
Jarrad Coffey, Behzad Ghadimi, Hamid Nikraz, Michele Rosano
}

\begin{abstract}
Haul road pavement design is often completed through application of axisymmetric linearelastic modelling. This may be implemented either through the derivation of cover curves employing the California Bearing Ratio, or within linear-elastic modelling completed by commercially available software. In recent years, a significant amount of research has been conducted on the application of the Finite Element Method for the analysis of pavements. A study to determine the accuracy of predicted haul road pavement response made by various linear-elastic and Finite Element Methods was undertaken. The deflected pavement surface profile was measured for three haul road pavement sections utilising terrestrial laser scanning, which also allowed measurement of the tyre/pavement contact geometry. Laboratory testing was completed to define the stiffness of each material through triaxial testing. Results of the field and laboratory testing allowed modelling via each method. Only minor variations were observed between the various linear-elastic modelling approaches that were investigated. In general, the Finite Element Method was found to produce the most accurate predictions. These findings provide the impetus for further investigation and the use of Finite Element Method for haul road pavement modelling.
\end{abstract}




\section{Introduction}

\subsection{Haul Road Design}

Mining and mineral processing often requires significant energy consumption. In 2012, $8.5 \%$ of the total energy consumed in Australia was consumed within the mining sector (Bureau of Resources and Energy Economics 2012). Estimates from the iron ore and coal industries suggest that up to $30 \%$ of the energy consumed in the production of an ore is consumed in bulk transport (Norgate and Jahanshahi 2011). One study suggests that 2.2 kilograms of diesel are consumed in the loading and hauling process for each tonne of iron ore produced in Australia (Norgate and Haque 2010). As a result, the efficient design and operation of haul road pavements which provide access between mining and processing or waste storage areas could provide energy savings by reducing road fuel costs and keeping tyre wear to a minimum (Department of Resources, Energy and Tourism 2012). A detailed investigation of the design of haul road pavements is required to support this premise.

Haul roads are critical assets in the mining of mineral ores, but typically employ unsurfaced flexible pavements designed with empirical techniques that often rely heavily on local experience (Thompson and Visser 2013). Most commonly, CBR-based design curves for specific vehicles are employed, often derived from procedures developed at the U.S. Army Engineers Waterways Experiment Station (Pereira 1977). This method relies on the singlelayer theory used by (Boussinesq 1885) in estimating deflection of the pavement at variable depths due to the design vehicle loading. The pavement and in-situ subgrade soil are considered as a semi-infinite, homogeneous, isotropic and elastic medium (Pereira 1977) in estimating the Equivalent Single Wheel Load (ESWL), which is then used to derive design cover curves. Although based on commonly accepted theory, this approach ignores recent modelling advances in the analysis of soil structures. A sub-grade failure theory considering vertical compressive strain as the limiting criteria has been validated against the above method by Wardle et al. (2001) for the pavement design software Airport Pavement Structural Design System (APSDS), a multi-layered linear-elastic program. Further advances have been made in pavement analysis through the use of the Finite Element Method (FEM). From the above discussion, it appears that haul road pavement design may be sensitive to the pavement structural analysis method utilised. 


\subsection{Flexible Pavement Design}

Flexible pavement design involves a multifaceted soil/tyre interaction problem, with the added complexity of interdependent material models. Unbound Granular Material (UGM) is the term used to describe materials that are granular in nature and do not have any internal binding action, which typically includes natural gravels and crushed rock (Vuong et al. 2008). It is generally accepted that they exhibit anisotropic behaviour (González et al. 2012), nonlinearity in the form of strain hardening such that an increase in resilient modulus occurs with an increase in bulk stress (Sahoo and Reddy 2010). Further, this resilient response influences the permanent strain response, which characterises the long-term performance of a pavement (Lekarp et al, 2000).

Design techniques for unbound, flexible pavements have evolved in recent decades. For heavy wheel loads, the method most commonly applied is the S77-1 method (Pereira 1977). This method was developed with the benefit of a regime of full-scale tests between the 1940's and the 1970's (White 2007). An introduction of larger aircraft saw the United States Department of Transportation Federal Aviation Administration seek an update of the theory through full-scale testing at the National Airport Pavement Testing Facility (NAPTF). This research is ongoing with recent updates being made to the sub-grade failure theory by Johnson (2016), to the extent that the S77-1 method is no longer used for the design of pavement loaded by modern large aircraft (Mitchell 2009).

\subsection{Pavement Modelling}

Detailed pavement modelling is available through the use of multi-layered linear-elastic theory and simulation with the Finite Element Method (FEM). Linear-elastic modelling is typically completed with software such as CIRCLY (Mincad Systems 2012a) or HIPAVE ( Mincad Systems, 2012b). Where linear-elasticity is assumed, the stress-strain relationship conforms to Hooks law (Hadi, MNS 1996; Ullidtz 2002; Huang 2003; Gedafa 2006; Ghadimi et al. 2013a, 2013b; Nega et al. 2013), and a closed form solution is possible. Programs such as HIPAVE and CIRCLY employ this theory, where the pavement structure is modelled as layered materials supported by an elastic half-space. Within closed-form solutions, the tyre loading is represented by a uniformly distributed pressure over a circular contact area. In the case of HIPAVE, and other programs developed for design with heavy wheel loads, the 
theory often includes the sub-layering procedure reported by Barker and Brabston (1975) to replicate the stress dependency of unbound granular materials (Wardle et al. 2005). Another feature adopted by some linear-elastic design tools is an assumption of cross-anisotropy, for which Austroads recommend an assumption of an anisotropic ratio (vertical to horizontal modulus) of two (González et al. 2012). These approximations and the restrictions inherent with axisymmetric modelling (discussed in Section 2.3) may be overcome through the application of FEM simulation (Ghadimi et al. 2013a).

FEM simulation analyses the mechanical response of a pavement structure to a prescribed loading. Within this process, a constitutive model relating soil response and material behaviour is required. This is commonly achieved with either of two characterisations; linear-elastic or nonlinear behaviour. Although a linear-elastic characterisation provides simplicity, it is incapable of modelling the nonlinear stress-dependency response of granular materials. The effect of nonlinear behaviour of granular materials has been investigated extensively (Fahey and Carter 1993; Hjelmstad and Taciroglu 2000; Kim and Tutumluer 2006; Kim et al. 2009; Ghadimi et al. 2013b; Wang and Al-Qadi 2013; Ghadimi and Nikraz 2016; Chegenizadeh et al. 2014). Recent researchers have used FEM to include the effect of nonlinearity of unbound granular materials (Li et al. 2017; Wang and Al-Qadi 2012; Al-Qadi et al. 2010). If materials are characterised as nonlinear, a closed form solution is not possible, and FEM is used to estimate the mechanical responses of the pavement. There are a number of nonlinear constitutive material models that have been developed for UGMs (González et al. 2012).

The following benefits of FEM highlighted by Sukumaran et al. (2004) may be beneficial in the analysis of heavily loaded, unsurfaced flexible pavements such as mine haul roads:

- two and three-dimensional calculation

- static, harmonic and transient dynamic simulated loading

- interface modelling with friction.

Lastly, linear-elastic modelling techniques can predict fictitious vertical tensile strains (Wardle et al. 2003). This can be avoided through the application of more sophisticated modelling in FEM (Dawson et al. 2008). 


\section{Material and Methods}

\subsection{Field Testing}

The field testing involved three different pavement sections on top of a mine waste dump. Each pavement section was selected as it had experienced differing volumes of traffic. Section 1 was within the access haul road onto the waste dump. Section 2 is likely to have experienced around half the traffic of Section 1, as it appeared to have been used to access approximately one-half of the waste dump. Section 3 was not within a designated access area and as such was expected to have experienced significantly less traffic than the other sections.

Pavement surface deflection under static wheel loading from a Komatsu 830E haul truck was measured via the use of a Leica C10 terrestrial laser scanner (Leica Geosystems 2015). Photogrammetric methods were also trialled for concurrent use in order to provide greater certainty. However, this required targets to be placed in the area of highest deflection, which presented practical challenges in safely accessing the area in close proximity to the haul truck tyres. In addition, these targets would have provided a shadow behind them in the laser scans, which may have prevented the maximum deflection being determined. The laser scanning procedure measured pavement rebound deflection by completing scans of the pavement surface in a $100 \mathrm{~mm}$ grid, with and without the truck in place, as illustrated in Figure 1. Registration of the two scans was completed automatically within the Leica Cyclone software (Leica Geosystems 2015) via recognition of defined (75mm square) targets placed within the scanned area during the acquisition of both scans (not shown in Figure 1). Both scans were then fitted with a TIN mesh, which smoothed localised deviations, and the surface elevation values were exported to a Microsoft Excel spreadsheet. This allowed the average displacement to be calculated for a small area, to eliminate curvature effects. The area of maximum deflection was found to occur between the two tyres, near the centre of the tyre contact areas. This process had previously been validated through model testing to an accuracy of $0.5 \mathrm{~mm}$. Pavement curvature in any direction could also be measured utilising the same approach. Determination of the deflection due to loading was determined from both an unloaded and fully loaded truck being tested on each pavement section. 


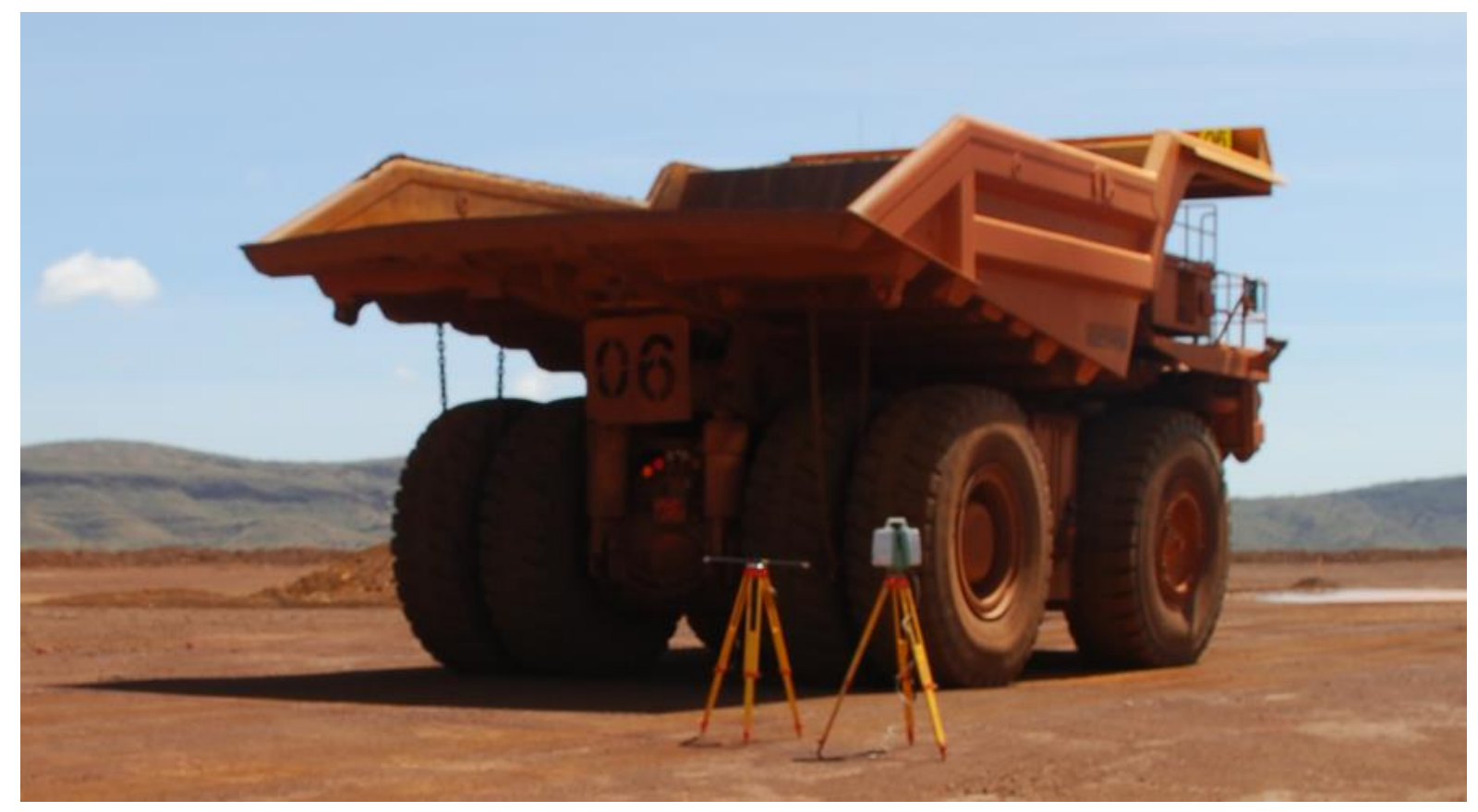

Figure 1: Laser scan of pavement deflection in progress with Komatsu 830E haul truck

Tyre/pavement contact geometry was also able to be determined from analysis of the laser scans. There was minor variation in the dimensions measured for each pavement section with all dimensions varying by between $5 \%$ and $7 \%$. The average dimensions of an unloaded rear axle dual-wheel gear (half a rear-axle) was $2.156 \mathrm{~m}$ transversely (' $\mathrm{M}$ ' in Figure 4) by $0.749 \mathrm{~m}$ longitudinally (' $\mathrm{L}$ ' in Figure 4), and the average dimensions of a loaded dual-wheel gear was $2.302 \mathrm{~m}$ transversely by $1.082 \mathrm{~m}$ longitudinally. Transverse dimensions include the space between tyres mounted to the same wheel gear, which averaged $378 \mathrm{~mm}$ for the unloaded truck and $317 \mathrm{~mm}$ for a loaded truck. The unique geometry measured for each pavement section was applied in the FEM modelling described in Section 2.4.

\subsection{Laboratory Testing}

Soil samples were collected from each pavement section and were subjected to a regime of laboratory testing. Particle size distribution testing was completed in accordance with AS 1289.3.6.1, which limited the maximum particle size to $37.5 \mathrm{~mm}$. It is possible much larger particles could have been present within the pavement at the deflection testing sites, especially at depth, as large particles near the surface would likely have been removed to assist in forming a smooth pavement surface. To facilitate triaxial testing, Maximum 
Modified Dry Density/Optimum Moisture Content (MDD/OMC) testing was completed in accordance with AS 1289.5.2.1.

Triaxial testing with monotonic loading was completed on samples at approximately 95\% MDD and OMC with the exception of the sample taken from Section 1, which was preserved in a sealed state for a number of weeks due to machine malfunction at the commencement of testing. This testing followed the approach presented in AS 1289.6.4.1, however, 100mm diameter samples were utilised in lieu of the ability to prepare an intact $67 \mathrm{~mm}$ diameter sample. The aspect ratio was maintained at two, with a sample height of $200 \mathrm{~mm}$ utilised throughout. Sample preparation followed the procedure of the Austroads Testing Methodology AG:PT/T053 (Austroads 2007). Multi-stage testing was completed at confining stresses of 30,100, 200 and $300 \mathrm{kPa}$, with a strain rate of $0.5 \%$ per minute. Laboratory setup of the triaxial testing is shown in Figure 2. The results were then utilised to determine the Mohr-Coulomb failure criteria and tangent elastic modulus (at a deviatoric stress of $890 \mathrm{kPa}$ ) of the material sampled from each pavement section.

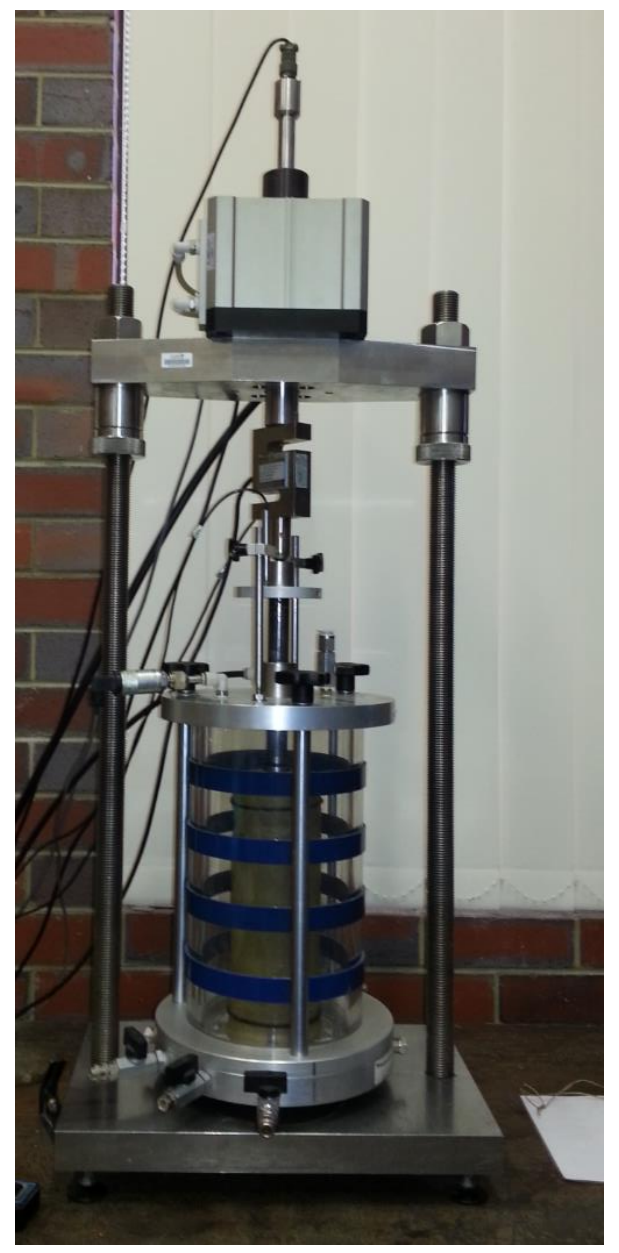

Figure 2: Triaxial testing laboratory setup. 


\subsection{Linear-elastic Modelling}

The pavement deflected profile under a Komatsu 830E haul truck load was calculated for the contact geometry and pavement structure shown in Figure 4. In all instances, the pavement was considered to be comprised entirely of base course material to a depth of two meters. For the purpose of all modelling, the subgrade was modelled as a linear-elastic material with an elastic modulus of $150 \mathrm{MPa}$ and Poisson's ratio of 0.3 . The elastic moduli of the various materials used in linear-elastic modelling are presented in Table 3.

Deflection was calculated by hand following the method employing Boussinesq's theorem, as detailed by the U.S. Army Corps of Engineers (Pereira 1977), and reproduced in Equation 1. Allowance for the influence of each of the six wheels fitted to the Komatsu 830E haul truck were calculated by means of the deflection factor, which was selected from the tabulated values within Pereira (1977). Variation in the deflection factor occurs due to the separation of each wheel, expressed as a ratio of a single wheel contact area width. This value is generally applied in the pavement design through the derivation of the ESWL, which is used to represent vehicle loading to determine the required pavement thickness.

$$
\Delta_{m}=\frac{p \cdot r}{E} \sum F_{M}
$$

Eq. 1 (Pereira, 1977)

The method above has been expanded by linear-elastic software, such as HIPAVE (Mincad Systems, 2012b) which was also utilised to calculate deflections. For a detailed explanation of the HIPAVE program, the reader is referred to the original CIRCLY user manual (Wardle 2004), the program from which it was derived, and the most recent HIPAVE user manual (2005). Pavement materials were considered linear-elastic and cross-anisotropic with an anisotropic ratio (ratio of vertical and horizontal elastic modulus) of two. HIPAVE utilises an axisymmetric geometry and therefore considers all wheel contact areas to be circular (see Figure 4), which distinguishes it from the FEM modelling discussed below. For application in HIPAVE, an equivalent radius was calculated that produced the same contact area as the measured rectangular contact areas. 
The HIPAVE software includes a sub-layering technique that approximates nonlinearity of unbound granular materials (2005), that was originally reported by Barker and Brabston (1975). Consequently, the applicability of the sub-layering technique reported by Barker and Brabston (1975) has been tested for use on haul road pavements with consideration of two different configurations. The first is the base being represented by a subbase quality material as per Barker and Brabston (1975), which is hereafter referred to the 'HIPAVE BarkerBrabston Subbase' case. A second case was also trialled with the base being separated into halves with the top half being represented by a base quality material as per Barker and Brabston (1975) and the bottom half being represented by a subbase quality material as per Barker and Brabston (1975). This second case is referred to as the 'HIPAVE Barker-Brabston Base/Subbase' case. It was not considered appropriate to model the entire pavement depth as base quality material, as laboratory testing (see Section 3.2) did not show the soils encountered in this study to be of base quality as per Barker and Brabston (1975) or the Federal Aviation Administration (FAA 2005). Lastly, a third case utilising linear-elastic modelling in HIPAVE was completed where all materials were isotropic, with the modulus values derived from the monotonic triaxial tests discussed above. This case is referred to as the 'HIPAVE Isotropic' case.

\subsection{Numerical Modelling}

The following provides some background and basis to the FEM. This method has been applied to flexible pavements as explained in detail in Ghadimi et al. (2016).

For elastic behaviour, the mechanical response of a medium can be calculated from Equation 2.

$$
\sigma=D \varepsilon
$$

FEM utilises an incremental approach, whereby the calculated strain in the current increment is used to estimate stress for the subsequent increment. Therefore, Equation 2 can be written in incremental format, as in Equation 3.

$$
\Delta \sigma=C \Delta \varepsilon
$$

Eq. 3 
Incorporation of the constitutive model is possible through application of the Jacobian matrix (D), which defines the relationship between strain and stress vectors. Within ABAQUS the constitutive matrix is computed incrementally through Equation 4:

$$
\begin{gathered}
d \Delta \boldsymbol{\sigma}=\frac{\partial \Delta \boldsymbol{\sigma}}{\partial \Delta \boldsymbol{\varepsilon}} d \Delta \boldsymbol{\varepsilon} \\
\frac{\partial \Delta \boldsymbol{\sigma}}{\partial \Delta \boldsymbol{\varepsilon}}=\boldsymbol{D}
\end{gathered}
$$

Eq. 4

ABAQUS enables the user to update the constitutive matrix for specific problems through the modification of the D matrix. If the material is characterised as linear-elastic, Hook's Law is utilised, as defined in Equation 5.

$$
\Delta \boldsymbol{\sigma}=2 G \Delta \varepsilon+\lambda I \Delta \varepsilon: I
$$

Eq. 5

Where:

I is the identity tensor

$\mathrm{G}$ is the shear modulus

$\lambda \quad$ is Lame's constant.

Under an isotropic assumption Equation 6 can be written.

$$
\left(\begin{array}{l}
\Delta \sigma_{11} \\
\Delta \sigma_{22} \\
\Delta \sigma_{33} \\
\Delta \tau_{12} \\
\Delta \tau_{23} \\
\Delta \tau_{31}
\end{array}\right)=\left(\begin{array}{cccccc}
2 G+\lambda & \lambda & \lambda & 0 & 0 & 0 \\
& 2 G+\lambda & \lambda & 0 & 0 & 0 \\
& & 2 G+\lambda & 0 & 0 & 0 \\
& & & G & 0 & 0 \\
& \text { Sym. } & & & G & 0 \\
& & & & & G
\end{array}\right)\left(\begin{array}{l}
\Delta \varepsilon_{11} \\
\Delta \varepsilon_{22} \\
\Delta \varepsilon_{33} \\
\Delta \gamma_{12} \\
\Delta \gamma_{23} \\
\Delta \gamma_{31}
\end{array}\right)
$$

Eq. 6 
In linear-elastic materials, constant values for $G$ and $\lambda$ are assumed, where both are functions of stress invariants for nonlinear materials. This is represented by Equation 7, where $\mathrm{G}$ and $\lambda$ are defined as a function of $M_{R}$ (resilient modulus). Note that $M_{R}$ is itself a function of stress invariants.

$$
\begin{gathered}
\lambda=\frac{M_{R} v}{(1+v)(1-2 v)} \\
G=\frac{M_{R}}{2(1+v)}
\end{gathered}
$$

Eq. 7

Within application of the above method, $\mathrm{M}_{\mathrm{R}}$ is updated according to the stress tensor within the previous increment. Finally, for the simulation to be completed, stress and strain equilibrium should be satisfied at the conclusion of each increment. The details of the method can be found in Ghadimi and Nikraz (2016).

FEM also involves decisions relating to the geometry and mesh of the pavement model. Ghadimi et al (2013) have compared the impact of varying mesh element types by comparing predicted pavement deflections to those taken from a linear-elastic analysis. Based on the recommendation from this study, eight node axisymmetric elements were adopted.

FEM was conducted with use of the program ABAQUS. The model geometry at the surface of the pavement is presented in Figure 4, where the overall model geometry has been selected in accordance with Kim and Tutumluer (2006) and Ghadimi and Nikraz (2016). The subgrade layer profile was arbitrarily selected (see Figure 3). Nonlinearity of the upper-most subgrade layer was represented by the $\mathrm{K}-\theta$ relationship discussed below for the base course. The remaining sub-grade layers had an elastic modulus calculated for the materials $\mathrm{K}-\theta$ relationship utilising the mean normal stress at the centre of each layer. In addition, a Poisson's ratio of 0.35 was adopted for all subgrade materials. This simplification of the subgrade conditions was employed in order to provide a practical simulation solution time. The model boundaries were represented by pin supports at the vertical faces and fully fixed (clamped) at the model base, as presented in Figure 3. The measured tyre/pavement contact geometry has been adopted for each model, with small variations in the contact pressure being made, as presented in Section 3.1. 
The unbound granular material from which the pavements were constructed was modelled as nonlinear. The approach previously proposed by Kim and Tutumluer (2006) was employed. Nonlinearity of materials is considered through a K- $\theta$ relationship, as discussed above.

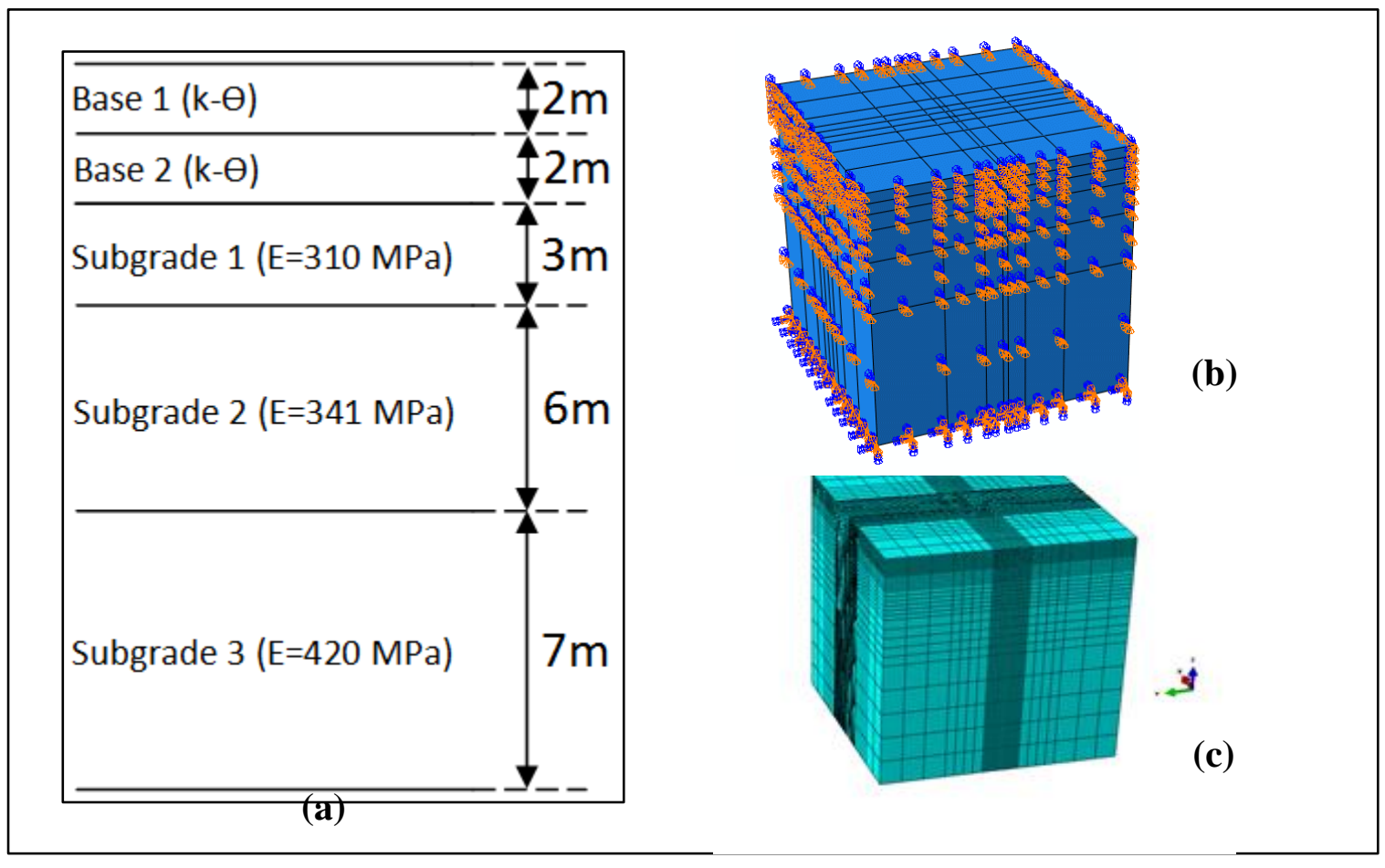

Figure 3: Pavement profile (a), FEM boundary conditions (b) and mesh adopted in FEM (c).

Finally, as stated previously, eight node axisymmetric elements have been used throughout this analysis. A minimum mesh size of 40x30x30 cm was utilised near the load centres. The mesh analysis conducted presented results that were found to be consistent with 70200 C3D8R elements. A finer mesh was trialled and found to have an immaterial impact on the calculated pavement response.

\subsection{Analysis and Comparison of Results}

Throughout the remainder of the paper, reference is made to maximum deflection and deflection at the centre of the rear axle. These terms refer to the deflection directly under the centroid of the contact area of one of the two dual wheel-gears present on the rear axle (Point A on Figure 4), and the deflection directly under the centre of the rear axle (Point B on Figure 
4). Similarly, the transverse curvature refers to the deflection profile of the pavement surface between the point of maximum deflection (Point A in Figure 4) and minimum deflection (Point B on Figure 4). Longitudinal curvature refers to the curvature between the points of maximum deflection (Point A on Figure 4) and a point at 2.44m in backward direction (Point C on Figure 4), outside the footprint of the truck. In both cases, the curvature is calculated as the ratio of maximum deflection to the deflection at an offset of $2.44 \mathrm{~m}$ (centre to centre distance between tyres) in the respective direction. This ratio was selected as it is the distance from the point of maximum deflection to a point directly beneath the mid-point of the rear axle.

Deflection at any point was reported to the nearest $0.1 \mathrm{~mm}$ for all measured and modelled results. As noted previously, the deflection measuring technique was only validated to an accuracy of $0.5 \mathrm{~mm}$, which produced some uncertainty with the results. This was overcome by testing the correlations between the predicted pavement deflection and the measured pavement deflection with the results stated an accuracy of $0.5 \mathrm{~mm}$.

A statistical analysis of the measured and modelled deflection was completed. Firstly, the mean variance between the measured and modelled maximum deflection was calculated for each modelling method. Secondly, the correlation coefficient between the six measured and predicted values of deflection and curvature values listed below was calculated for each modelling method. This statistic provides insight into the consistency of the modelling method in predicting the pavement response and ensuring that the calculated mean variance was not significantly influenced by outliers. The correlation coefficient between measured and predicted values for each of the following was then calculated for each of the six load scenarios.

- maximum deflection

- deflection at the centre of the rear axle

- transverse curvature

- longitudinal curvature

Comparison of results relating to maximum deflection was considered to be the primary indicator of accuracy for each modelling method, as it was expected to be the most powerful indicator of the maximum vertical subgrade strain, which is typically used to estimate the life 
of a flexible pavement. Secondly, the results relating to curvature provided further insight into the accuracy of the modelling methods.

\section{Results and Discussion}

\subsection{Field Tests}

A comparison of the measured tyre/pavement contact geometry and how this was adopted for each modelling method is presented in Figure 4. Specific values for each pavement section and load case are presented in Table 1. The mean tyre/pavement contact pressures shown in Table 2 were calculated from the known wheel load and measured contact area. The contact pressure was assumed to be constant for all modelling methods. It was considered necessary to make this assumption in the absence of the contact pressure distribution being measured in the field tests and authors such as Wong (2009) suggesting that the pressure distributions between off-the-highway tyres and soil are likely unique. This assumption may lead to differences between the results of FEM simulation and field measurement (Wang et al. 2012 and Wang et al. 2013). 


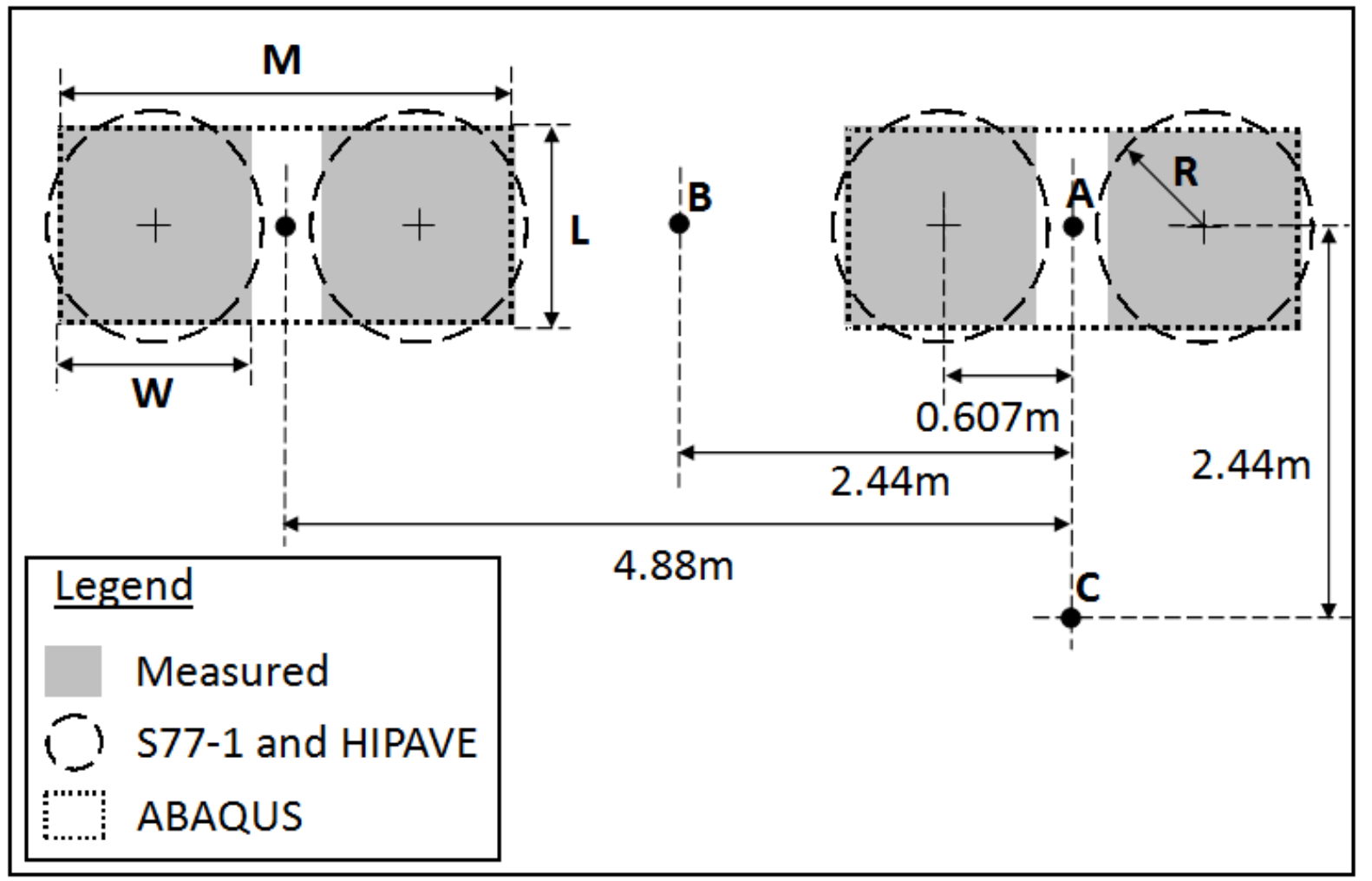

Figure 4: Tyre contact geometry measured in field tests and used for respective modelling methods (rear axle only front axle not shown).

Table 1: Measured and modelled tyre/pavement contact geometry.

\begin{tabular}{|c|c|c|c|c|c|c|c|c|}
\cline { 2 - 9 } \multicolumn{1}{c|}{} & \multicolumn{4}{c|}{ Unloaded Truck } & \multicolumn{4}{c|}{ Loaded Truck } \\
\hline Section & $\mathrm{W}(\mathrm{mm})$ & $\mathrm{L}(\mathrm{mm})$ & $\begin{array}{c}\mathrm{M} \\
(\mathrm{mm})\end{array}$ & $\mathrm{R}(\mathrm{mm})$ & $\begin{array}{c}\mathrm{W} \\
(\mathrm{mm})\end{array}$ & $\mathrm{L}(\mathrm{mm})$ & $\begin{array}{c}\mathrm{M} \\
(\mathrm{mm})\end{array}$ & $\begin{array}{c}\mathrm{R} \\
(\mathrm{mm})\end{array}$ \\
\hline 1 & 877 & 739 & 2155 & 454 & 1019 & 996 & 2381 & 568 \\
\hline 2 & 893 & 761 & 2107 & 465 & 920 & 1125 & 2281 & 574 \\
\hline 3 & 898 & 709 & 2181 & 450 & 963 & 1045 & 2244 & 566 \\
\hline
\end{tabular}

Table 2: Tyre contact pressure included in modelling.

Tyre/Pavement Contact Pressure 


\begin{tabular}{|c|c|c|}
\cline { 2 - 3 } \multicolumn{1}{c|}{} & \multicolumn{2}{c|}{$(\mathrm{kPa})$} \\
\hline Section & Unloaded Truck & Loaded Truck \\
\hline 1 & 311 & 620 \\
\hline 2 & 297 & 607 \\
\hline 3 & 317 & 624 \\
\hline
\end{tabular}

The laser scanning techniques described in Section 2.1 produced the maximum deflection values in Table 3. It should be noted that the values presented are stated to an accuracy of $0.1 \mathrm{~mm}$, whereas the terrestrial laser scanning method used has only been validated to an accuracy of $0.5 \mathrm{~mm}$. The values in Table 3 are presented at this accuracy as they are used in subsequent analysis. The results appear consistent with the relative compactive effort that each section is thought to have experienced from haul truck traffic, as outlined in Section 2.1.

Table 3: Maximum measured deflection with variation in wheel load

\begin{tabular}{|c|c|c|}
\cline { 2 - 3 } \multicolumn{1}{c|}{} & \multicolumn{2}{c|}{ Maximum Deflection (mm) } \\
\hline Section & Unloaded Truck & Loaded Truck \\
\hline 1 & 1.2 & 2.6 \\
\hline 2 & 2.0 & 3.8 \\
\hline 3 & 1.9 & 5.2 \\
\hline
\end{tabular}

\subsection{Laboratory Tests}

Particle size distribution testing showed the material from the three sections to be well graded or poorly graded gravels in accordance with AS 1726 (Standards Australia, 1993), with 2-4\% passing the $0.075 \mathrm{~mm}$ sieve. As presented in Figure 5, section two had a significantly larger sand fraction than the other two materials. From observation of the materials in the field, the maximum particle size was $100-150 \mathrm{~mm}$, with a range of $0-25 \%$ exceeding $37.5 \mathrm{~mm}$. The MMDD of the materials was relatively consistent and varied from 2.4 to $2.58 \mathrm{t} / \mathrm{m} 3$. 


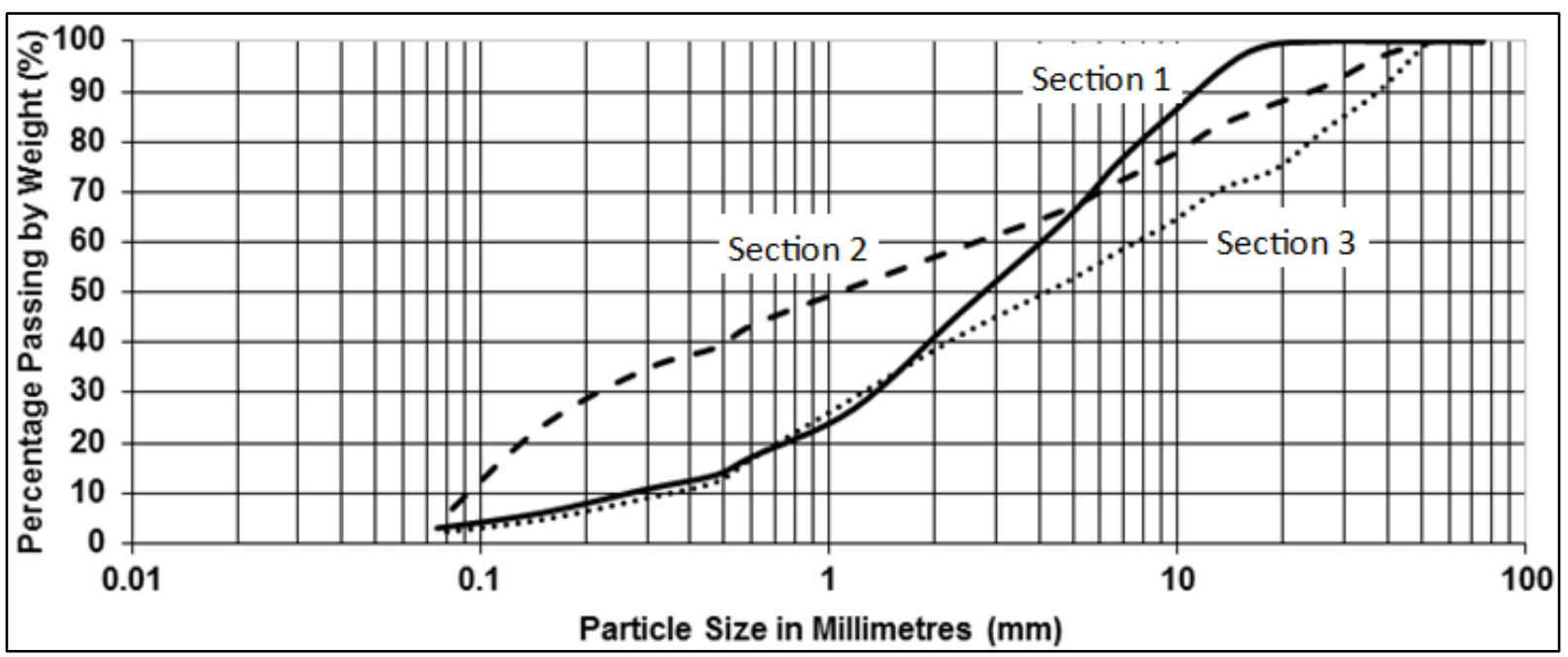

Figure 5: Particle Size Distributions for the pavement materials.

The constitutive models derived from monotonic triaxial tests are presented in Table 4. Values of the internal angle of friction and elastic modulus values (at a mean normal stress of $890 \mathrm{kPa}$ ) in Table 4 suggest there is some consistency between materials. Additionally, the k$\Theta$ functions show each material to exhibit significant nonlinear behaviour.

Table 4: Material model results arising from laboratory testing

\begin{tabular}{|c|c|c|c|}
\hline Section & Elastic Modulus (MPa) & $\mathrm{k}-\Theta$ (Monotonic) & $\varnothing$ (degrees) \\
\hline 1 & 271 & $\mathrm{M}_{\mathrm{R}}=1.996 . \Theta^{0.783}$ & 39 \\
\hline 2 & 254 & $\mathrm{M}_{\mathrm{R}}=8.522 . \Theta^{0.586}$ & 39 \\
\hline 3 & 255 & $\mathrm{M}_{\mathrm{R}}=9.530 . \Theta^{0.597}$ & 40 \\
\hline
\end{tabular}

\subsection{Numerical Modelling}

Figure 6 shows an example of the deformed mesh predicted by ABAQUS, along with contours of deflection and Mises stress. From Figure 9 it is clear that neither induced stress or 
displacements are influenced by the modelled boundary conditions. Therefore, it appears the selected model geometry did not influence the results.

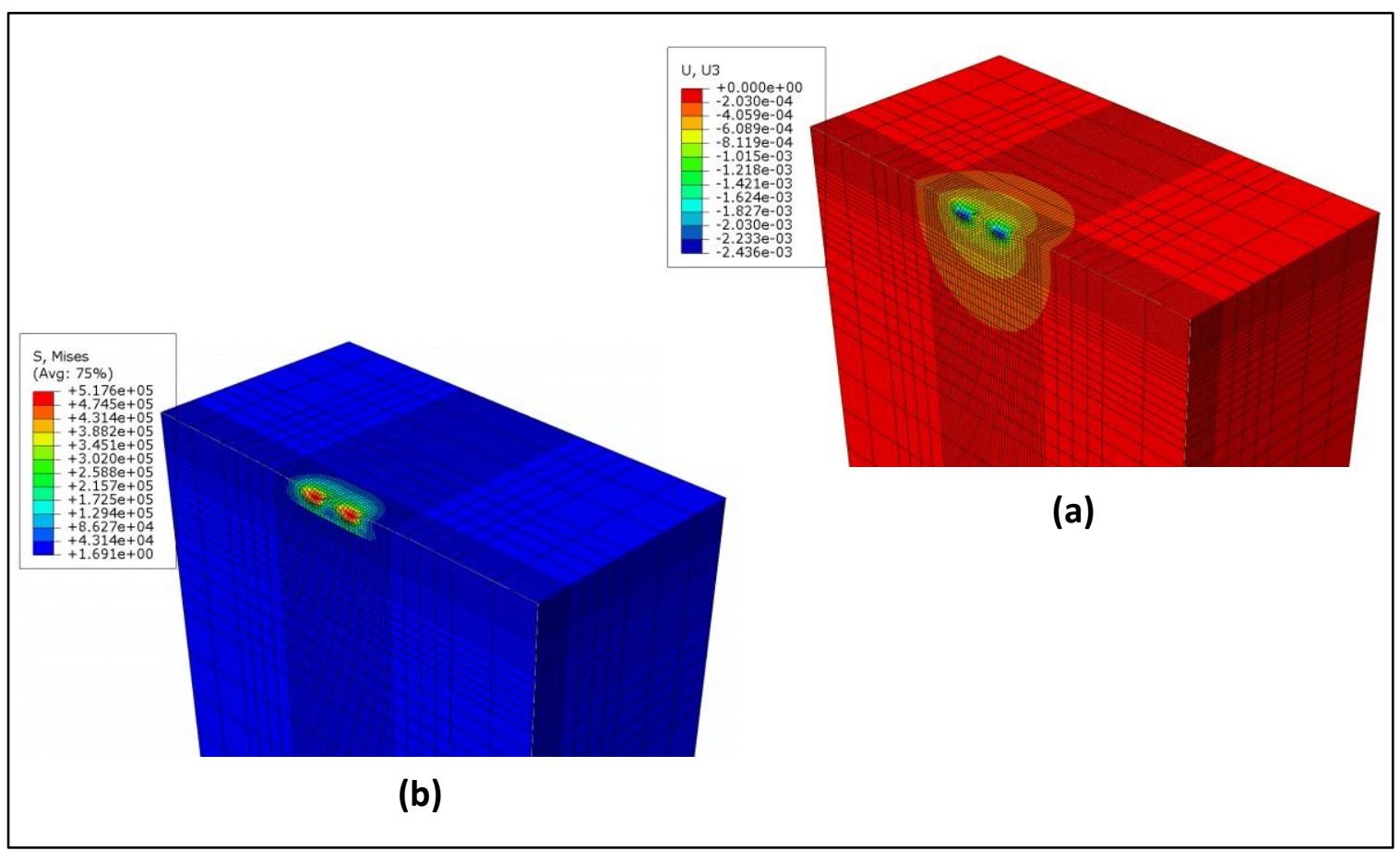

Figure 6: Typical contours of the surface deflection (a) and Mises stress (b) in the FEM model.

Figure 7 and Figure 8 present a comparison of the measured and predicted longitudinal and transverse curvature. Although maximum deflection values can be read from these figures, they are shown more clearly in Figure 9. As can be seen, nonlinear modelling of materials conducted in FEM (ABAQUS) predicts the maximum deflection with the greatest accuracy. However, in some cases curvature predicted by linear-elastic methods appear to provide a closer fit to the measured results. Vertical compressive subgrade strain is most commonly the critical pavement response used in the design of haul road pavements, which cannot be predicted by observation of deflection alone, and as such, the curvature was also considered in judging the efficacy of each modelling method. Consequently, the inconsistency of the variance between the measured and predicted curvature warrants further investigation, such as the statistical analysis discussed below. 
The maximum deflection at the centre of the rear axle for Section 1 was not predicted well by any of the modelling methods, see Figure 7. This may be due to wheel load interaction effects associated with the $\mathrm{k}-\Theta$ constitutive model that results in lower stiffness than the pavement material applied in the other sections. FEM (ABAQUS) provided the best prediction of this value, but still produced a significant error. Similarly, the longitudinal deflection measured for Section 2 was not predicted well by any method. This may have resulted from the presence of an isolated area of soft soil within the pavement or subgrade immediately below the wheel loads.

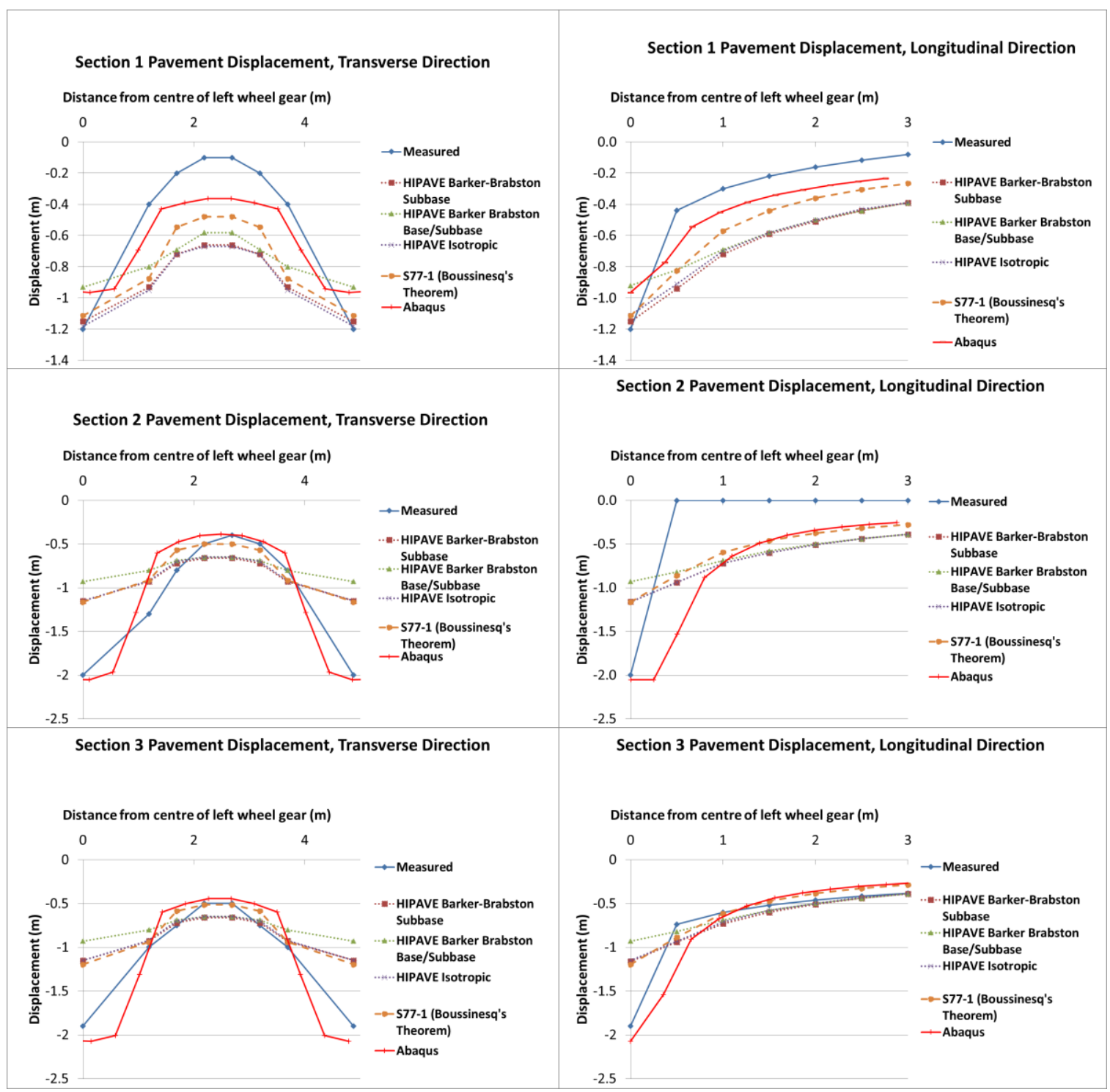

Figure 7: Measured deflection for each pavement section with an unloaded truck. 
The over-prediction of the measured longitudinal curvature for Section 2 is replicated for the results relating to the loaded truck, see Figure 8 . However, measured deflection was greater for the loaded case, which has resulted in the predicted curvature values being a closer fit than for the unloaded case. Another notable result presented in Figure 8 is the underprediction of the deflection at the centre of the rear axle for Section 3. This may have resulted due to greater wheel load interaction being predicted as a result of the nonlinear $\mathrm{k}-\theta$ constitutive model for the base course in the FEM (ABAQUS) for Section 3 compared to the other sections.

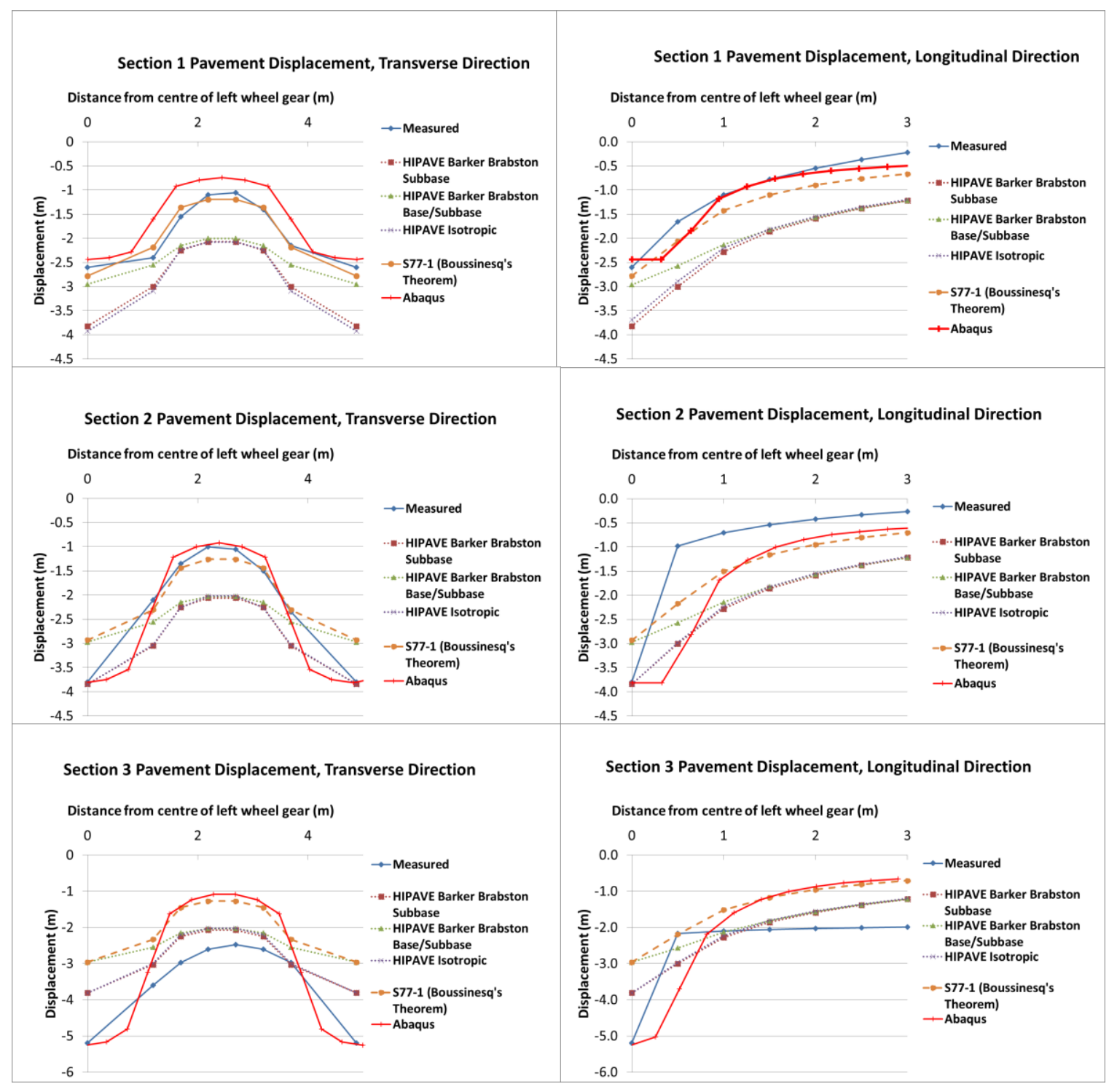

Figure 8: Measured deflection for each pavement section with a loaded truck. 
In order to summarise the results presented above, a statistical analysis was undertaken. Table 5 presents the mean variance between measured and predicted values for deflection and curvature. From observation of this table, it is clear that FEM modelling (ABAQUS) produces the most accurate prediction of the measured deflection and curvature. Additionally, Table 5 shows relative consistency of the predictions produced by the various linear-elastic modelling methods. Due to its wide use in developing CBR design curves, and relative accuracy in comparison to other linear-elastic analysis methods in Table 5, the S77-1 method is used to judge the efficacy of linear-elastic modelling throughout the remainder of this paper.

Table 5: Mean variance of predicted from measured values.

\begin{tabular}{|l|c|c|c|}
\cline { 2 - 4 } \multicolumn{1}{c|}{} & \multicolumn{3}{c|}{ Average Variance from Measured Value (\%) } \\
\hline Modelling Method & Maximum Deflection & Transverse Curvature & $\begin{array}{c}\text { Longitudinal } \\
\text { Curvature }\end{array}$ \\
\hline HIPAVE BB Subbase & 26.6 & 45.7 & 35.8 \\
\hline $\begin{array}{l}\text { HIPAVE BB } \\
\text { Base/Subbase }\end{array}$ & 34.4 & 66.1 & 55.6 \\
\hline HIPAVE Isotropic & 26.4 & & 35.2 \\
\hline S77-1 & 26.5 & 45.5 & 34.5 \\
\hline ABAQUS & 6.5 & 38.4 & 22.4 \\
\hline
\end{tabular}

Figure 9 provides a visual comparison of the ability of linear-elastic and FEM analyses to predict the measured deflections. Although a very simplistic mode of analysis, from Figure 9 it appears that the utilisation of S77-1 analysis may under-design pavements as it consistently underestimates the measured maximum deflection. A broader study is recommended to further investigate this observation. 


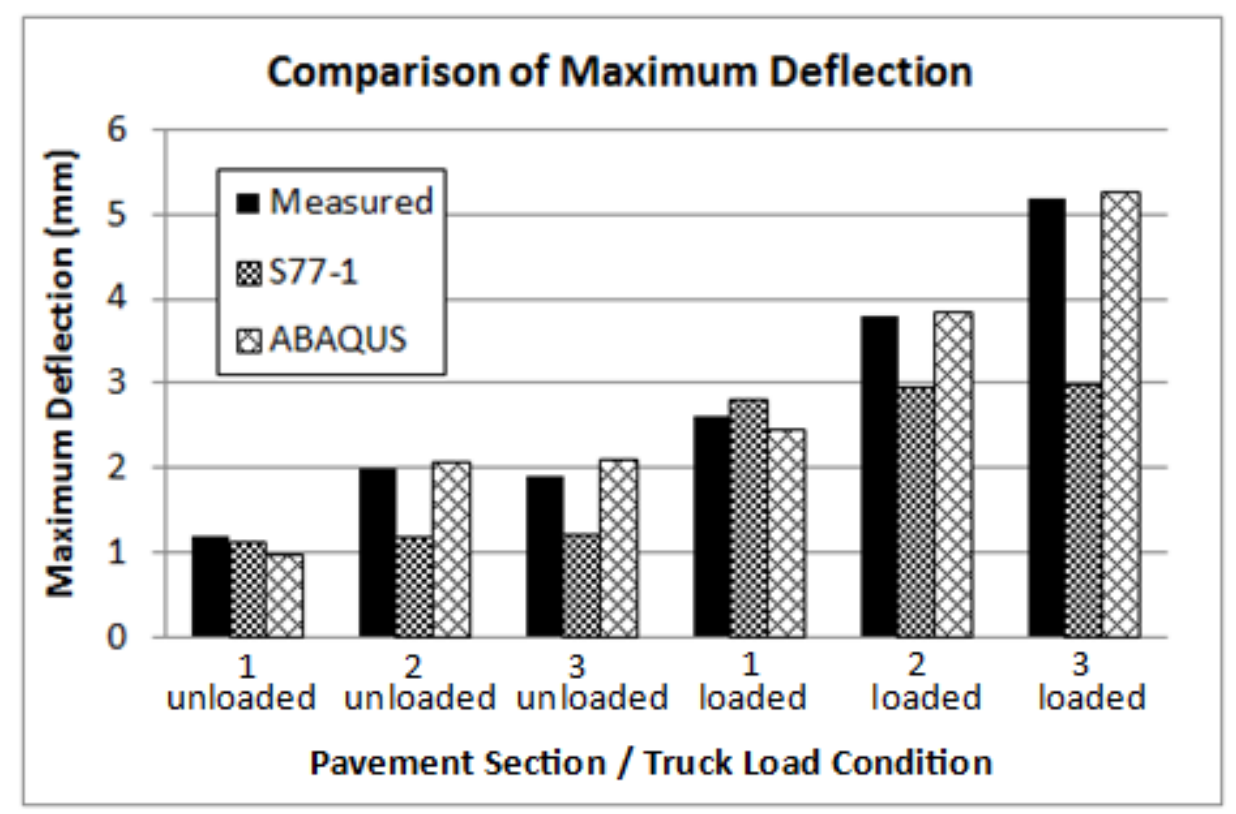

Figure 9: Comparison of measured and modelled maximum deflections.

Simply comparing the mean variance between the measured and predicted deflection and curvature for each method may be misleading. For example, a large overestimate of the maximum deflection for one section may be offset be a large underestimation for another section. Consequently, the analysis outlined in Section 2.5 has been completed, with the results presented in Table 6. Statistically, for six samples and a level of significance of 0.05 , the observed trend can be relied on if the correlation coefficient exceeds 0.874 (University of New England, 2015). Therefore, the qualitative assessment from observation of Figure 9 that FEM (ABAQUS) consistently produces more accurate predictions of the measured maximum deflections than the S77-1 methodology is supported by the statistical analysis. However, the correlation coefficients in Table 6 have been calculated with measured pavement deformation measured to an accuracy of $0.1 \mathrm{~mm}$, whereas the measuring method has only been validated to an accuracy of $0.5 \mathrm{~mm}$. For this reason, the correlation coefficients relating to maximum deflection were also recalculated with the measured deflections with an accuracy of $0.5 \mathrm{~mm}$. On review, the correlation coefficients for maximum deflection calculated by S77-1 and ABAQUS remained unchanged. 
Table 6: Comparison of the correlation coefficient between measured (to an accuracy of $0.1 \mathrm{~mm}$ ) and predicted results.

\begin{tabular}{|l|c|c|c|c|}
\cline { 2 - 5 } \multicolumn{1}{c|}{} & \multicolumn{4}{c|}{ Correlation Coefficient with Measured Pavement Response } \\
\hline \multirow{3}{*}{ Modelling } & Maximum & $\begin{array}{c}\text { Deflection at } \\
\text { Centre of Rear }\end{array}$ & $\begin{array}{c}\text { Transverse } \\
\text { Curvature }\end{array}$ & $\begin{array}{c}\text { Longitudinal } \\
\text { Curvature }\end{array}$ \\
\hline Method & Deflection & Axle & 0.795 & 0.870 \\
\hline ABAQ-1 & 0.843 & 0.773 & 0.897 & 0.882 \\
\hline
\end{tabular}

Some caution needs to be used in considering the various results relating to curvature presented above, due to the noted validated accuracy of the measurement via laser scanning. However, it appears that FEM (ABAQUS) produces the most accurate estimates of pavement deflection directly under the centre of the rear axle of the haul truck, as presented in Table 6. Therefore, it is unsurprising that FEM (ABAQUS) is also shown to produce more accurate curvature predictions. This finding suggests that the nonlinear behaviour approximated in FEM (ABAQUS) modelling has a significant impact on the predicted pavement response, given the superior predictions to that produced by the S77-1 method, which assumes all soil within the pavement and sub-grade behaves in a linear-elastic manner. Although this result is promising it is anticipated that greater detail may be required to eliminate the observed variations between measured and predicted response in the isolated cases discussed above. Consequently, it appears likely that the constitutive model adopted for characterisation of the pavement and sub-grade materials has the potential to have a significant impact on the accuracy of the predicted service life for a haul road pavement.

\subsection{Current Design Practice}

The results above show that FEM is able to most accurately predict the surface deflection of a haul road with a single-layer unbound pavement. It appears likely that FEM is also able to more accurately predict the deflection and compressive strains generated in the sub-grade, which govern the design curves developed via the S77-1 method and the damage models adopted in linear-elastic software used for mechanistic-empirical design. Although the utilisation of FEM for haul road pavement design would provide greater demands on testing 
for pavement and sub-grade material characterisation and the designer's time, it should be considered in the future. Based on the inaccuracy of the methods considered in this study it seems likely that pavements designed with cover curves generated by the S77-1 method or through linear-elastic software will perform unsatisfactorily in at least some instances. Given that a miner's output relies, at least to some extent, on the condition of the site's haul roads, excessive maintenance requirements and/or loss of production has the potential to impact the profitability of a mining operation. The results of this paper are focussed on a single pavement layer above the sub-grade. It is recommended that multi-layer pavements are investigated in the future, as it is possible that FEM is better able to account for interaction between multiple layers. Lastly, linear-elastic modelling is typically required for the incorporation of stabilised pavement layers in haul road pavement design. FEM may provide superior prediction of the response of a stabilised pavement and should be investigated further in the future.

\section{Conclusions}

From the results the following conclusions are made:

FEM completed with ABAQUS has been shown to produce significantly more accurate predictions of the measured deflection and curvature than any of the linear-elastic modelling methods trialled in this study. The primary difference between the two modelling approaches is the nonlinear constitutive relationship in the FEM modelling. Consequently, it appears that the inclusion of nonlinearity produces a more accurate prediction of haul road pavement response to haul truck loading. Therefore, it is suggested that FEM is the most proficient of the methods trialled for predicting pavement response.

The predicted pavement deflections calculated with the S77-1 method produced similar results to the HIPAVE analysis. Therefore, it appears that the haul road pavement designs generated through the use of linear-elastic software are unlikely to vary significantly from designs produced by the S77-1 method. One caveat to this recommendation is when stabilised, bound or coarse rock layers are included within the pavement design, which are not able to be included in the S77-1 method. 
The approximation of nonlinearity of pavement material behaviour through the sub-layering technique proposed by Barker et al (1975) appears to have a minor impact on the results of linear-elastic modelling for the cases included in this study.

The following recommendations are made:

The above study should be repeated with measurement of pavement strain and/or deflection to assess the efficacy of each modelling method in greater detail.

The CBR curves derived with the S77-1 method may be used for the design of unbound haul road pavements composed solely of UGMs in lieu of linear-elastic software which adopt subgrade damage models derived from the S77-1 method. Benefits of the S77-1 method include simplicity in determining material input parameters (CBR values for each layer), reduced calculation time and repeatability once cover curves have been derived for a given design vehicle.

Further investigation of the S77-1 method should be undertaken for haul roads to determine if the linear-elastic analysis underpinning the resulting design curves adequately predicts measured deflection. Areas for further research include investigation of the accuracy of constants included in the method to approximate wheel load interaction and the accuracy of the deflections calculated at depth that govern the pavement thickness.

Whilst nonlinear 3DFEM modelling has generally produced more accurate predictions of the measured pavement deflections, greater accuracy was achieved by linear-elastic methods for isolated cases. Such cases should be investigated further to determine if nonlinear constitutive material models included in the FEM contributed to the poor accuracy in such cases.

At present these is no pavement failure theory for nonlinear 3D FEM modelling and as such efforts should be made to develop a failure theory in order to utilise the FEM method for haul road pavement design in the future.

FEM should be further investigated and compared to linear-elastic modelling for designs incorporating:

1. Multi-layered haul road pavements

2. Haul truck wheel-load interaction

3. Haul road pavements with modified/stabilised layers 


\section{Acknowledgements}

The authors wish to acknowledge Rio Tinto for granting access to the mine site and haul truck used in the completion of the research detailed in this paper.

\section{References}

Al-Qadi, Imad, Hao Wang, and Erol Tutumluer. "Dynamic analysis of thin asphalt pavements by using cross-anisotropic stress-dependent properties for granular layer." Transportation Research Record: Journal of the Transportation Research Board 2154 (2010): 156-163.

Austroads. Commentary To Ag : Pt / T053 - Determination of Permanent Deformation and Resilient Modulus Characteristics of Unbound Granular Materials Under Drained Conditions. 2007.

Barker WR, Brabston WN. Development of a Structural Design Procedure for Flexible Airport Pavements. Vicksburg, Miss.; 1975.

Boussinesq J. Application des Potentiels a l'etude de l'equilibre et du Mouvement de s Solids Elastiques ; . Gauthier-Villars Paris. 1885

Bureau of Resources and Energy Economics. Key facts Australia’s Energy Sector. 2013.

Chegenizadeh, Amin, Behzad Ghadimi, Hamid Nikraz, and Mesut Simsek. "A novel twodimensional approach to modelling functionally graded beams resting on a soil medium." Structural Engineering and Mechanics 51, no. 5 (2014): 727-741.

CIRCLY 5.1. Melbourne, Australia: Mincad Systems Pty Ltd.; 2012a.

Dawson A, Kolisoja P, Vuorimies N. Understanding Low-Volume Pavement Response to Heavy Traffi c Loading. RoadexIII North Peripher. 2008

Department of Resources, Energy and Tourism. Analyses of diesel use for mine haul and transport operations; 2012.

FAA. Advisory Circular AC 150/5370-10B: Standards for specifying construction of airports. 2005. 
Fahey M, Carter JP. A finite element study of the pressuremeter in sand using a nonlinearelastic plastic model. Can Geotech J. 1993;30(2):348-62.

Gedafa DS. Comparison of Flexible Pavement Performance Using Kenlayer and Hdm-4. In: idwest Transportation Consortium. Ames, Iowa; 2006.

Ghadimi B, Nikraz H, Rosano M. Dynamic simulation of a flexible pavement layers considering shakedown effects and soil-asphalt interaction. Transp Geotech . 2016; $7: 40-58$.

Ghadimi B, Asadi H, Nikraz H, Leek C. Effects of geometrical parameters on numerical modeling of pavement granular material. In: Airfield and Highway Pavement 2013: Sustainable and Efficient Pavements - Proceedings of the 2013 Airfield and Highway Pavement Conference. ASCE; 2013a

Ghadimi, Behzad, and Hamid Nikraz. "A comparison of implementation of linear and nonlinear constitutive models in numerical analysis of layered flexible pavement." Road Materials and Pavement Design 18, no. 3 (2017): 550-572.

Ghadimi B, Nikraz H, Leek C, Nega A. A Comparison between Effects of Linear and Nonlinear mechanistic behaviour of materials on the Layered Flexible Pavement Response. Transp Res Board. 2013b;723(1215):12-21.

González A, Bodin D, Jameson G, Oeser M, Vuong B. Development of a nonlinear finite element pavement response to load model. Sydney, NSW 2000 Australia; 2012.

Hibbit D, Karlsson B, Sorenson. P. ABAQUS reference manual 6.10. Cambridge, MA: Dessault Systemmes; 2011.

Hadi, MNS and MS. Computing Stresses in Road Pavements Using Circly, Msc/Nastran and Strand6. Trans Inst Eng Aust Civ Eng. 1996;38(2-4):89-93.

HIPAVE User Manual. Richmond South, Victoria 3121 Australia: Mincad Systems Pty Ltd.; 2005.

HIPAVE 5.0. Melbourne, Australia: Mincad Systems Pty Ltd; 2012b.

Hjelmstad KD, Taciroglu E. Analysis and Implementation of Resilient Modulus Models for Granular Solids. J Eng Mech. 2000;126(8):821-30. 
Huang YH. Pavement Analysis and Design. New Jersey, USA: Prentice-Hall Inc.; 2003.

Johnson D. Airport pavement design and evaluationAirport pavement design and evaluation. Draft AC 150/5320-6F FAARFIELD software. ACC Summer Workshop, August 10. 2016.

Kim M, Tutumluer E. Modeling Nonlinear, Stress Dependent Pavement Foundation Behavior Using a General-Purpose Finite Element Program. ASCE Geotech Spec Publ Pavement Mech Perform. 2006

Kim M, Tutumluer E, Kwon J. Nonlinear Pavement Foundation Modeling for ThreeDimensional Finite-Element Analysis of Flexible Pavements. Int J Geomech. 2009; 9(5):195-208.

Leica Geosystems. Leica Geosystems . Leica CloudWorx. Cyclone 8.1.3; 2015.

Li, Maoyun, Hao Wang, Guangji Xu, and Pengyu Xie. "Finite element modeling and parametric analysis of viscoelastic and nonlinear pavement responses under dynamic FWD loading." Construction and Building Materials 141 (2017): 23-35.

Mitchell G. FAA pavement design: AC 150/5320-6E - FAARFIELD. 2009 PCC Workshop. Indiana Chapter - American Concrete Pavement Association. January 27. 2009.

Nega A, Nikraz H, Leek C, Ghadimi B. Evaluation and Validation of Characterization Methods for Fatigue Performance of Asphalt Mixes for Western Australia. Innov Sustain Technol Road Airf Pavement. 2013;723:75-85.

Norgate T, Haque N. Energy and greenhouse gas impacts of mining and mineral processing operations. J Clean Prod. 2010;18(3):266-74.

Norgate T, Jahanshahi S. Reducing the greenhouse gas footprint of primary metal production: Where should the focus be? Miner Eng. 2011;24(14):1563-70.

Pereira AT. Instruction report S-77-1. Procedures for the development of CBR design curves. Washington, D.C.; 1977.

Sahoo UC, Reddy KS. Effect of nonlinearity in granular layer on critical pavement responses of low volume roads. Int J Pavement Res Technol. 2010;3(6):320-5.

Sukumaran B, Chamala N, Willis M, Davis J, Jurewicz S, Kyatham V. Three Dimensional 
Finite Element Modeling of Flexible Pavements. In: In 2004 FAA Worldwide Airport Technology Transfer Conference Atlanta 2004. 2004.

Thompson R, Visser A. Mine Haul Road Design, Construction And Maintenance Management. 2013. p. 1-39.

Ullidtz P. Analytical tools for design of flexible pavements. In: In Keynote Address delivered at the 8th ISAP Conference held in Copenhagen. 2002. p. 1-16.

Vuong, B. Jameson, G. Sharp K. AGPT04A/08 Guide to pavement technology part 4A: granular base and subbase materials. Sydney, NSW 2000 Australia; 2008.

Wang, Hao, Imad L. Al-Qadi, and Ilinca Stanciulescu. "Effect of surface friction on tirepavement contact stresses during vehicle maneuvering." Journal of Engineering Mechanics 140, no. 4 (2013): 04014001.

Wang, Hao, and Imad L. Al-Qadi. "Importance of nonlinear anisotropic modeling of granular base for predicting maximum viscoelastic pavement responses under moving vehicular loading." Journal of engineering mechanics 139, no. 1 (2012): 29-38.

Wang, Hao, Imad L. Al-Qadi, and Ilinca Stanciulescu. "Simulation of tyre-pavement interaction for predicting contact stresses at static and various rolling conditions." International Journal of Pavement Engineering 13, no. 4 (2012): 310-321.

Wong, J,Y. "Terramechanics and off-road vehicle engineering. Terrain behaviour, off-road vehicle performance and design". 2009. Butterworth-Heinemann. ISBN 9780750685610.

Wardle L. CIRCLY Theory and background manual. Richmond South, Victoria 3121 Australia: Mincad Systems Pty Ltd; 2004.

Wardle L, Rodway B, Rickards I. Calibration of Advanced Flexible Aircraft Pavement Design Method to S77-1 Method. In: 27th International Air Transportation Conference. Illinois, USA; 2001. p. 192-201-0-7844-0579-6.

Wardle L, Youdale G, Rodway B. Current issues for mechanistic pavement design. In: Proceedings of the 21st AARB . Queensland, Australia; 2003.

Wardle LJ, Rickards I, Hudson K. Hipave - a Mechanistic Design Tool for Heavy-Duty 
Industrial Pavements. In: AAPA 2005 Pavements Industry Conference. Queensland, Australia; 2005. p. 18-21.

White GW. An investigation of the Australian layered elastic tool for flexible aircraft pavement thickness design . Qut. Queensland University of Technology; 2007. 